\title{
Noteworthy Cardiovascular Involvement with Sporadic Late-onset Nemaline Myopathy
}

\author{
Kosuke Matsuzono ${ }^{1}$, Theerawat Kumutpongpanich ${ }^{2}$, Kana Kubota ${ }^{3}$, Takafumi Okuyama ${ }^{3,4}$, \\ Kohei Furuya ${ }^{1}$, Tomoya Yagisawa ${ }^{1}$, Akie Horikiri ${ }^{1}$, Takeshi Igarashi ${ }^{1}$, Kumiko Miura ${ }^{1}$, \\ Tadashi Ozawa ${ }^{1}$, Takafumi Mashiko ${ }^{1}$, Haruo Shimazaki ${ }^{1}$, Reiji Koide ${ }^{1}$, Ryota Tanaka ${ }^{1}$, \\ Hayato Shimizu ${ }^{3,4}$, Yasushi Imai ${ }^{3}$, Kazuomi Kario ${ }^{3}$, Ichizo Nishino ${ }^{2}$ and Shigeru Fujimoto ${ }^{1}$
}

\begin{abstract}
:
Cardiac involvement has recently been the focus of sporadic late-onset nemaline myopathy (SLONM). However, right ventricular failure and pulmonary hypertension, in addition to repetitive cardiac arrest, are noteworthy characteristics of SLONM. We herein report a 66-year-old woman with SLONM whose main symptoms were cardiac arrest, right ventricular failure, and pulmonary hypertension. Despite permanent pacemaker replacement, cardiac arrest occurred repetitively, and even with continuous positive airway pressure, right ventricular failure and pulmonary hypertension persisted. The patient was finally diagnosed with SLONM by a muscle biopsy. Our case suggests the possibility of cardiovascular involvement in SLONM, especially right ventricular failure and pulmonary hypertension.
\end{abstract}

Key words: SLONM, autonomic failure, right ventricular failure, pulmonary hypertension, BiPAP

(Intern Med 60: 2327-2332, 2021)

(DOI: 10.2169/internalmedicine.6068-20)

\section{Introduction}

A form of myopathy characterized by unique cytoplasmic aggregates known as nemaline bodies is defined as nemaline myopathy (NM) (1). Currently, NM is regarded as a heterogeneous disease, and the onset in most cases occurs during childhood due to the mutation of causative genes (2). However, non-inherited subacute progressive NM cases with an onset during adulthood are also observed.

Sporadic late-onset nemaline myopathy (SLONM) is a rare and acquired type of myopathy that was described for the first time in 1966 (3). SLONM is characterized by proximal muscle atrophy and weakness, and the presence of nemaline bodies in muscle biopsies (4). Monoclonal gammopathy of undetermined significance (MGUS) or human immunodeficiency virus (HIV) were associated with the most recent SLONM case reports (5-7). Common clinical symptoms of SLONM are muscle atrophy and weakness, head drop, respiratory involvement, and dysphagia (8). In contrast, cardiovascular failure is rarely reported or recognized as a symptom of SLONM.

We herein report a woman with SLONM without associated MGUS or HIV and whose initial and main symptoms were cardiovascular involvement.

\section{Case Report}

A 66-year-old woman who developed heart failure complicated by pulmonary arterial hypertension was transferred to our hospital. The patient's clinical record is shown in Table 1 . She provided informed consent to participate in this study. She had no family history of related diseases. At the age of 14, she had severe scoliosis, but her perinatal and infant histories were free from clinical conditions. At the age of 27 , she had bradycardia with a heart rate of about $30 /$

\footnotetext{
${ }^{1}$ Division of Neurology, Department of Medicine, Jichi Medical University School of Medicine, Japan, ${ }^{2}$ Department of Neuromuscular Research, National Institute of Neuroscience, National Center of Neurology and Psychiatry, Japan, ${ }^{3}$ Division of Cardiovascular Medicine, Department of Medicine, Jichi Medical University School of Medicine, Japan and ${ }^{4}$ Department of Cardiology, Sano Kosei General Hospital, Japan Received: August 11, 2020; Accepted: January 5, 2021; Advance Publication by J-STAGE: February 22, 2021 Correspondence to Dr. Kosuke Matsuzono, kmatsuzono51@jichi.ac.jp
} 
Table 1. Patient's Clinical Record.

\begin{tabular}{lll}
\hline $\begin{array}{c}\text { Age } \\
\text { (years) }\end{array}$ & \multicolumn{1}{c}{ Symptom } & \multicolumn{1}{c}{ Examination and treatment } \\
\hline 14 & Scoliosis was revealed & \\
27 & Bradycardia of HR 30/min & \\
39 & Cardiac arrest & Myocardial biopsy (diagnosis unknown) \\
& (due to complete AV block) & Permanent pacemaker placement \\
40 & Cardiac arrest (cause unknown) & \\
46 & Cardiac arrest (cause unknown) & \\
47 & Cardiac arrest (cause unknown) & \\
62 & Sleep apnea & CPAP initiation \\
66 & Right ventricular failure & Muscle biopsy (SLONM diagnosed) \\
& Pulmonary hypertension & BiPAP initiation \\
\hline AV: atrioventricular, BiPAP: bilevel positive airway pressure, CPAP: continuous positive airway \\
pressure, HR: heart rate, SLOMN: sporadic late-onset nemaline myopathy
\end{tabular}

min. Thereafter, she was not further evaluated, and followup did not involve any intervention. She delivered 3 children normally when she was 23,25 , and 32 .

However, she suffered her first cardiac arrest followed by complete atrioventricular block at the age of 39. She was transferred to our hospital [Jichi Medical University Hospital (JMUH)], and spontaneous circulation was regained after cardiopulmonary resuscitation. A dual-chamber permanent pacemaker was implanted, but no underlying diseases related to the complete atrioventricular block were detected at that time, despite performing a cardiovascular work-up, including a myocardial biopsy Only conventional hematoxylin and eosin staining was employed at that time, so nemaline bodies were not observed.

Although her pacemaker worked well and lethal ventricular arrhythmia was not documented, she repetitively experienced cardiopulmonary arrest at the ages of 40, 46, and 47. In each episode, she was transferred to Sano Kosei General Hospital (SKGH), and spontaneous circulation was regained each time. At the age of 62, she had her pacemaker generator exchanged, and a new ventricular lead was inserted because of ventricular lead failure. In addition, at the age of 62, she was diagnosed with sleep apnea, and continuous positive airway pressure (CPAP) was initiated during sleep.

At the age of 66, she developed heart failure, mainly involving the right part of the heart, and was emergently admitted to SKGH. At that time, echocardiography showed a severely impaired left ventricular function (approximately $20 \%$ ejection fraction), which was diagnosed as transient neurogenic cardiomyopathy (i.e., Takotsubo cardiomyopathy). Although her left ventricular function gradually improved, mitral regurgitation and pulmonary hypertension persisted (estimated pulmonary artery pressure of approximately $60 \mathrm{mmHg}$ ). She was treated with a combination of diuretics and positive-pressure ventilation.

On further evaluations, she was referred to the Division of Cardiovascular Medicine of JMUH. An electrocardiogram showed all ventricular pacing rhythms with dissociated slow atrial beats, reflecting sinus node dysfunction. Since her atrial lead was not captured at all, the pacemaker mode setting was changed from atrial-synchronized ventricularinhibited (VDD) to ventricular rate responsive demand (VVIR). An arterial blood gas analysis showed chronic type II respiratory failure $\left(\mathrm{PaCO}_{2}=60.2 \mathrm{mmHg}, \quad \mathrm{PaO}_{2}=44.6\right.$ $\mathrm{mmHg}$, and $\mathrm{HCO}_{3}=32.5 \mathrm{mmL} / \mathrm{L}$ in room air). An examination of the respiratory function showed restrictive ventilator impairment $(67.2 \%$ vital capacity, $68.1 \%$ forced vital capacity, and $105.8 \%$ forced expiratory volume $\%$ in 1 second). A radiograph showed severe scoliosis (Figure A). We reexamined the echocardiography findings, which showed that the left ventricular function had recovered, despite the presence of pacing-induced dyssynchrony and disappearance of the pulmonary hypertension/right-sided pressure overload. We performed catheterization to confirm the hemodynamics and clinical diagnosis and observed a low cardiac output and normalized pulmonary arterial and right ventricle/atrium pressure (mean pulmonary arterial pressure $=16 \mathrm{mmHg}$, pulmonary capillary wedge pressure $=4 \mathrm{mmHg}$, pulmonary vascular resistance $=4.8$ Wood). We ultimately diagnosed her heart failure as having been caused by a combination of respiratory failure, pulmonary hypertension related to hypoventilation and an impaired ventricular function, suggesting the possibility of systemic muscular-skeletal disorders that cover both respiratory and circulatory phenotypes.

Although her cardiac dynamics improved temporarily, three months later, her echocardiography results showed the recurrence of pulmonary hypertension/right-sided pressure overload without severe involvement of the left ventricular function; tricuspid regurgitation pressure gradient=51.6 $\mathrm{mmHg}$, estimated pulmonary arterial pressure $=66.6 \mathrm{mmHg}$, ejection fraction $=58.1 \%$. Eccentric remodeling was also revealed: interventricular septum thickness $=9.1 \mathrm{~mm}$, posterior wall diameter $=10.0 \mathrm{~mm}$. Finally, she was transferred to the neurology division.

A neurological assessment showed that her cognitive function was preserved (Mini-Mental State Examination score of 26/30 and Frontal Assessment Battery score of 17/ 18). She did not display head drop or dysphagia. Her ster- 


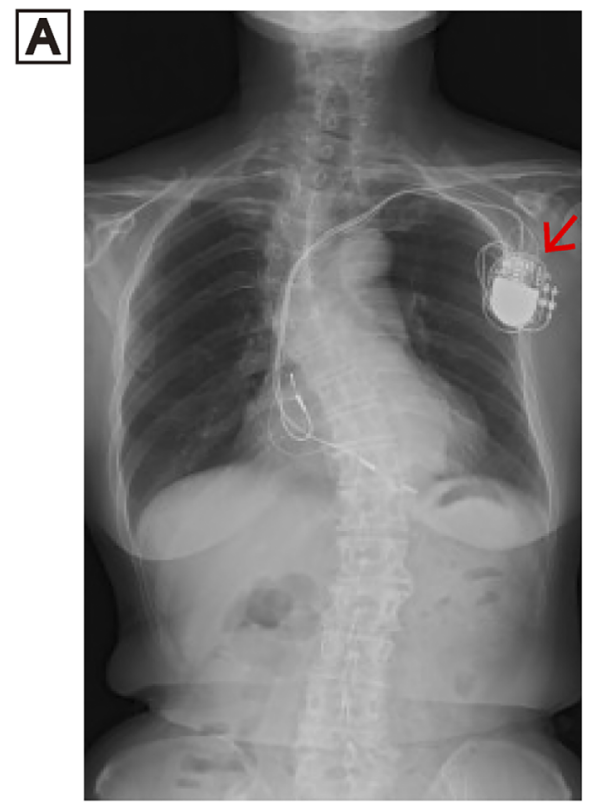

E

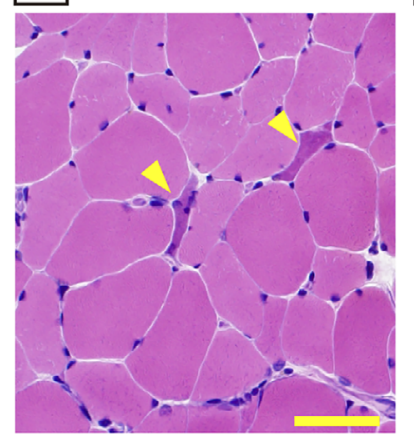

$\mathrm{H}$

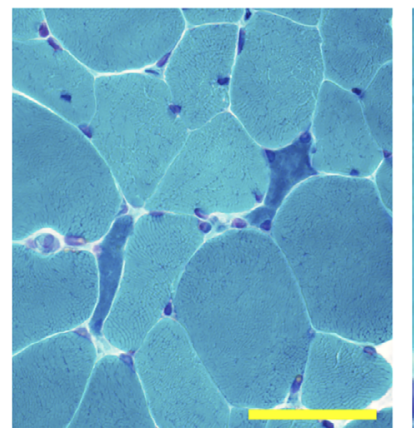

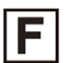

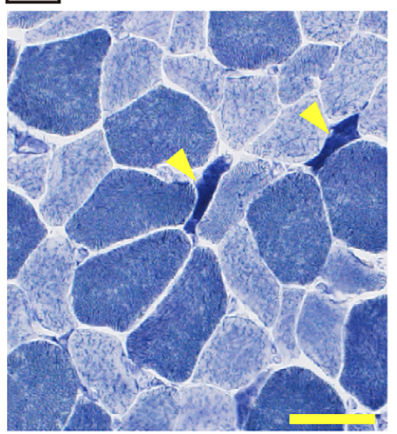

I

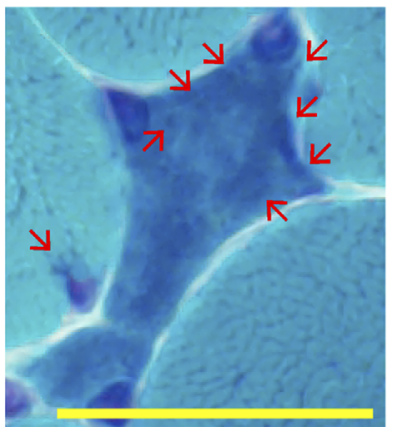

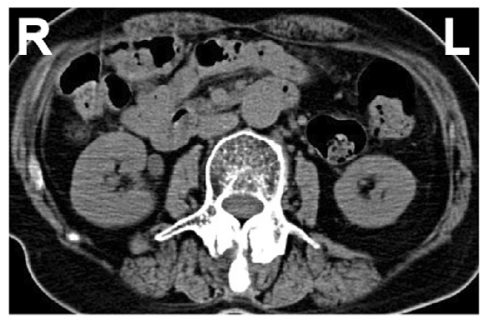

C

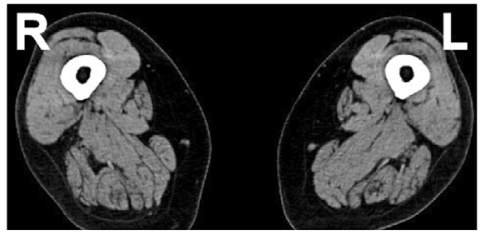

D

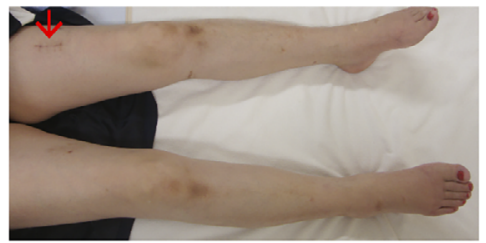

G
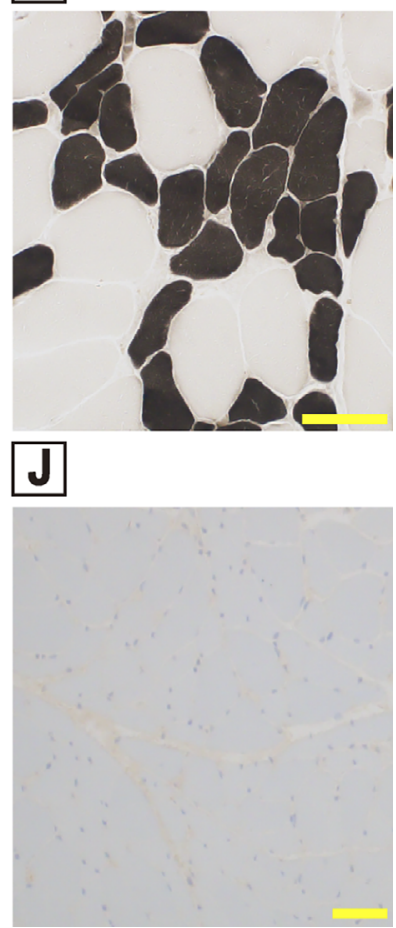

Figure. (A) A radiograph showing severe scoliosis. The arrow indicates the pacemaker. (B) Computed tomography showing paraspinal and (C) quadriceps and hamstrings atrophy. (D) Image of the patient's lower legs. The arrow indicates the muscle biopsy scar. Muscle biopsy examinations (E-J). (E) Hematoxylin and Eosin staining. (F) NADH-TR staining. Arrowheads indicate small angular fibers, but no cytoplasmic aggregate was detected. (G) ATPase staining showing type 2 fiber atrophy and the appearance of some type $2 \mathrm{C}$ fibers. Modified Gomori trichrome staining at a lower magnification $(\mathbf{H})$ and a higher magnification (I). Arrows showing numerous nemaline bodies present in the small angular fibers. (J) MxA immunofluorescence, staining-negative. Scale bars=50 $\mu \mathrm{m}$.

nocleidomastoid, paraspinal, quadriceps, and hamstring muscles were atrophic (Figure B, C). Gowers' sign was positive, which suggested limb muscle weakness. She had no sensory disturbance. She exhibited deep tendon hyperreflexia in her bilateral biceps, triceps, barachioradialis, and patellar tendons. In addition, right Babinski and right Trömner's re- flexes were positive. Severe orthostatic hypotension was present from 112/92 $\mathrm{mmHg}$ in the lying position to $72 / 48$ $\mathrm{mmHg}$ in the standing position.

Hematological and biochemical analyses showed kidney dysfunction, as evidenced by a high serum blood urea nitrogen level of $58 \mathrm{mg} / \mathrm{dL}$ and a high serum creatinine level of 
Table 2. Typical and Atypical Symptoms of SLONM in the Present Case.

\begin{tabular}{lcc}
\hline \multicolumn{1}{c}{ Systems } & Typical & Untypical \\
\hline $\begin{array}{l}\text { Skeletal } \\
\text { Muscle }\end{array}$ & Scoliosis & \\
& Atrophy \\
Gowers' sign (+) & \\
Respiratory & Type II respiratory failure & \\
Cardiovascular & & Complete AV block \\
& Cardiac arrest \\
& & Right ventricular failure \\
& & Pulmonary hypertension \\
& & Orthostatic hypotension \\
Reflex & Hyperreflexia \\
& Trömner (+) \\
& & Babinski (+) \\
\hline AV: atrioventricular, SLONM: sporadic late-onset nemaline myopathy
\end{tabular}

$2.00 \mathrm{mg} / \mathrm{dL}$. The level of serum creatinine kinase was normal (17 U/L), and the test result for both MGUS and HIV was negative.

Although her muscle weakness was subtle and the serum creatinine kinase level was not elevated, we performed a muscle biopsy from the atrophic left femoral rectus muscle (Figure C, D) and conducted several histochemical analyses (Figure E-J). Hematoxylin and eosin staining showed only mild to moderate variation in fiber size, and small angular fibers were observed (Figure E). However, nemaline bodies were detected in the small angular fibers, when modified Gomori trichrome (mGT) staining was performed (Figure $\mathrm{H}, \mathrm{I})$. Immunofluorescence staining was negative for the myxovirus resistance protein, a marker of dermatomyositis (Figure J). We also performed whole-exome sequencing for the patient, but no pathologic substitution in the ACTAl, NEB, KLHL, TPM, TNNT, CFL2, LMOD3, KBTBD13, $M Y P N, M Y O 18 B$, or RYR genes was detected. Based on the results of the muscle biopsy and gene examination, we finally diagnosed the patient with SLONM.

We introduced CPAP after treatment of her cardiac and respiratory failure and allowed her to be discharged. However, she was soon re-admitted to our hospital due to heart failure. We considered the CPAP to have been insufficient and therefore initiated bilevel positive airway pressure (BiPAP) during sleep with treatment for her chronic heart failure. In accordance with a previous review (4), we also added immunomodulatory therapy, intravenous immunoglobulin (400 mg/kg for 5 days) and oral prednisolone intake $(15 \mathrm{mg} /$ day $)$. After this additional treatment, her daily living activities were preserved without heart failure or pulmonary hypertension.

\section{Discussion}

Although scoliosis and respiratory involvement are common SLONM symptoms, it was difficult to diagnose SLONM in the present case because the initial and main symptom was cardiovascular involvement, including heart failure, pulmonary hypertension, and rhythm disturbances. In addition, she displayed hyperreflexia and positive Trömner and Babinski reflexes, which are atypical findings in patients with SLONM. A long period of 27 years passed until the final diagnosis of SLONM was made. The echocardiogram and intracardiac electrocardiogram findings obtained from her pacemaker also demonstrated sinus node dysfunction, suggesting that her conduction had been systematically damaged by SLONM. The typical and atypical symptoms for SLONM in the present case are summarized in Table 2.

Most previous reports on SLONM have focused on respiratory involvement with associated MGUS or $\operatorname{HIV}(5,6)$. However, cardiac involvement has recently been observed not only in patients with congenital NM (9) but also in those with $\operatorname{SLONM}(7,10)$. Sarullo et al. reported a 37year-old SLONM man who suffered from left ventricular failure with dyspnea and tachycardia (10). In that case, heart failure was revealed after presenting severe weakness and hypotonia of proximal limb muscles. Monforte et al. analyzed six SLONM cases and reported cryptogenic cardiac involvement in all cases (7). Conduction abnormalities or arrhythmias were identified in all six cases in their report, consistent with our case. While left ventricular failure was also reported in those previous reports, the right ventricular failure and pulmonary hypertension in our case are new notable features of SLONM. Table 3 shows a comparison between the previously reported cases of cardiac involvement following SLONM and our present case.

We speculate that two pathologies were associated with the symptoms of SLONM in the present case. One is chronic type II respiratory failure, which was associated with right ventricular failure (cor pulmonale) and pulmonary hypertension (11). A major cause of this pathology is considered to be chronic hypoxia, which leads to pulmonary arterial vasoconstriction and a cascade of molecular and biochemical events, culminating in vascular smooth muscle hypertrophy (12). The other pathology associated with the 
Table 3. Comparison between the Previous Reported Cardiac Involvement Cases Following SLONM and Our Present Case.

\begin{tabular}{|c|c|c|c|c|c|c|}
\hline Reference & $\begin{array}{l}\text { Pt. } \\
\text { No }\end{array}$ & Sex & $\begin{array}{l}\text { Onset } \\
\text { age }\end{array}$ & $\begin{array}{l}\text { Symptoms at } \\
\text { onset }\end{array}$ & $\begin{array}{l}\text { Left atrial/ventricu- } \\
\text { lar involvement }\end{array}$ & $\begin{array}{l}\text { Right atrial/ } \\
\text { ventricular } \\
\text { involvement }\end{array}$ \\
\hline \multirow[t]{6}{*}{7} & $\# 1$ & M & 39 & $\begin{array}{l}\text { Proximal upper } \\
\text { limb weakness } \\
\text { Neck extensor } \\
\text { weakness }\end{array}$ & $\begin{array}{l}\text { Mild EF reduction } \\
(51 \%)\end{array}$ & None \\
\hline & \#2 & $\mathrm{F}$ & 73 & $\begin{array}{l}\text { Proximal lower } \\
\text { limb weakness } \\
\text { Neck extensor } \\
\text { weakness }\end{array}$ & $\begin{array}{l}\text { Left ventricular } \\
\text { hypertrophy } \\
\text { Left ventricular } \\
\text { diastolic dysfunction }\end{array}$ & $\begin{array}{l}\text { Atrial } \\
\text { tachycardia } \\
\text { runs }\end{array}$ \\
\hline & \#3 & $\mathrm{F}$ & 65 & $\begin{array}{l}\text { Proximal lower } \\
\text { limb weakness } \\
\text { Neck extensor } \\
\& \text { flexor } \\
\text { weakness }\end{array}$ & $\begin{array}{l}\text { Left ventricular } \\
\text { hypertrophy } \\
\text { Left ventricular } \\
\text { diastolic dysfunction } \\
\text { Left atrial } \\
\text { enlargement }\end{array}$ & $\begin{array}{l}\text { 1st degree AV } \\
\text { block }\end{array}$ \\
\hline & $\# 4$ & M & 64 & $\begin{array}{l}\text { Proximal upper } \\
\& \text { lower limb } \\
\text { weakness } \\
\text { Neck extensor } \\
\text { weakness }\end{array}$ & $\begin{array}{l}\text { Mild EF reduction } \\
(50 \%) \\
\text { Left ventricular } \\
\text { hypokinesia }\end{array}$ & $\begin{array}{l}\text { Permanent } \\
\mathrm{AF}\end{array}$ \\
\hline & $\# 5$ & M & 47 & $\begin{array}{l}\text { Proximal upper } \\
\& \text { lower limb } \\
\text { weakness } \\
\text { Neck extensor } \\
\text { weakness }\end{array}$ & $\begin{array}{l}\text { Mild EF reduction } \\
(52 \%) \\
\text { Left ventricular } \\
\text { hypokinesia } \\
\text { Non-sustained VT }\end{array}$ & None \\
\hline & \#6 & $\mathrm{F}$ & 68 & $\begin{array}{l}\text { Proximal lower } \\
\text { limb weakness } \\
\text { Neck extensor } \\
\text { weakness }\end{array}$ & None & $\begin{array}{l}\text { Paroxysmal } \\
\text { AF }\end{array}$ \\
\hline 10 & \#7 & M & 37 & $\begin{array}{l}\text { Proximal upper } \\
\text { limb weakness }\end{array}$ & $\begin{array}{l}\text { Left ventricular } \\
\text { systolic dysfunction } \\
\text { EF reduction }(20 \%)\end{array}$ & None \\
\hline Present case & $\# 8$ & $\mathrm{~F}$ & 39 & Cardiac arrest & $\begin{array}{l}\text { Takotsubo } \\
\text { cardiomyopathy } \\
\text { EF reduction }(20 \%)\end{array}$ & $\begin{array}{l}\text { Complete AV } \\
\text { block } \\
\text { Permanent } \\
\text { pacemaker } \\
\text { placement } \\
\text { Right } \\
\text { ventricular } \\
\text { failure } \\
\text { Pulmonary } \\
\text { hypertension }\end{array}$ \\
\hline
\end{tabular}

AF: atrial fibrillation, AV: atrioventricular, EF: ejection fraction, F: female, M: male, SLOMN: sporadic lateonset nemaline myopathy

symptoms of SLONM in the present case is cardiac involvement as the initial manifestation of NM. An undetermined conduction system disorder or cardiomyopathy is associated with NM, and sudden cardiac death without any prefixes has occasionally been reported $(7,10,13)$. Some may argue that the aforementioned manifestations may be caused by alveolar hypoventilation syndrome or other congenital muscular diseases as differential diagnoses. Still others argue that one NM pathology is the combination of features of actinassociated myopathy and myofibrillar myopathy, as various genes coding for actin-binding proteins are causative for NM $(14,15)$. One NM causative gene, cofilin2, is involved in sacrometric actin exchange and muscle maintenance (16). We speculate that sinus or atrioventricular node dysfunction alone was not the cause of our patient's cardiopulmonary arrest, as her arrests repeatedly occurred even while the pacemaker was working. More advanced studies are therefore needed, although it is possible that the disturbance in muscle maintenance or pulmonary hypertension itself may be due to cardiac involvement, as in our present case.

Scoliosis and orthostatic hypotension were also evident in our case. Scoliosis is possible in all congenital myopathies but is more characteristic in the early phase of certain NM $(17,18)$. A positive Babinski reflex suggests supranuclear paralysis over the L4 level, while a positive Trömner's reflex suggests that this occurs over the C6-T1 level. We speculate that her right positive Babinski and Trömner's reflexes were due to scoliosis. A previous report based on NM 
autopsy cases shows nemaline bodies aggregate not only in the skeletal muscle but also in the smooth muscle (19). We speculate that the disturbance in the vascular skeletal muscle also occurred and caused orthostatic hypotension in our present case.

In conclusion, the present case alerts clinicians to the possible cause of SLONM as a cardiovascular and respiratory disorder.

The authors state that they have no Conflict of Interest (COI).

\section{Financial Support}

This study was partly supported by an Intramural Research Grant (29-4) for Neurological and Psychiatric Disorders of NCNP.

\section{Acknowledgement}

We appreciate the cooperation of the patient.

\section{References}

1. Shy GM, Engel WK, Somers JE, Wanko T. Nemaline myopathy. A new congenital myopathy. Brain 86: 793-810, 1963.

2. Miyatake S, Mitsuhashi S, Hayashi YK, et al. Biallelic mutations in MYPN, encoding myopalladin, are associated with childhoodonset, slowly progressive nemaline myopathy. Am J Hum Genet 100: 169-178, 2017.

3. Engel AG. Late-onset rod myopathy (a new syndrome?): light and electron microscopic observations in two cases. Mayo Clin Proc 41: 713-741, 1966.

4. Schnitzler LJ, Schreckenbach T, Nadaj-Pakleza A, et al. Sporadic late-onset nemaline myopathy: clinico-pathological characteristics and review of 76 cases. Orphanet J Rare Dis 12: 86, 2017.

5. Maeda MH, Ohta H, Izutsu K, Shimizu J, Uesaka Y. Sporadic late-onset nemaline myopathy as a rare cause of slowly progressive muscle weakness with young adult onset. Muscle Nerve 51: 772-774, 2015.

6. Uruha A, Benveniste O. Sporadic late-onset nemaline myopathy with monoclonal gammopathy of undetermined significance. Curr Opin Neurol 30: 457-463, 2017.
7. Monforte M, Primiano G, Silvestri G, et al. Sporadic late-onset nemaline myopathy: clinical, pathology and imaging findings in a single center cohort. J Neurol 265: 542-551, 2018.

8. Chahin N, Selcen D, Engel AG. Sporadic late onset nemaline myopathy. Neurology 65: 1158-1164, 2005.

9. Finsterer J, Stollberger C. Review of cardiac disease in nemaline myopathy. Pediatr Neurol 53: 473-477, 2015.

10. Sarullo FM, Vitale G, Di Franco A, et al. Nemaline myopathy and heart failure: role of ivabradine; a case report. BMC Cardiovasc Disord 15: 5, 2015.

11. Han MK, McLaughlin VV, Criner GJ, Martinez FJ. Pulmonary diseases and the heart. Circulation 116: 2992-3005, 2007.

12. Stenmark KR, Fagan KA, Frid MG. Hypoxia-induced pulmonary vascular remodeling: cellular and molecular mechanisms. Circ Res 99: 675-691, 2006.

13. Marseglia L, D'Angelo G, Manti S, et al. Sudden cardiac arrest in a child with nemaline myopathy. Ital J Pediatr 41: 20, 2015.

14. Nowak KJ, Wattanasirichaigoon $\mathrm{D}$, Goebel $\mathrm{HH}$, et al. Mutations in the skeletal muscle alpha-actin gene in patients with actin myopathy and nemaline myopathy. Nat Genet 23: 208-212, 1999.

15. Donner K, Ollikainen $M$, Ridanpää $M$, et al. Mutations in the beta-tropomyosin (TPM2) gene--a rare cause of nemaline myopathy. Neuromuscul Disord 12: 151-158, 2002.

16. Gurniak CB, Chevessier F, Jokwitz M, et al. Severe protein aggregate myopathy in a knockout mouse model points to an essential role of cofilin2 in sarcomeric actin exchange and muscle maintenance. Eur J Cell Biol 93: 252-266, 2014.

17. Ferreiro A, Quijano-Roy S, Pichereau C, et al. Mutations of the selenoprotein $\mathrm{N}$ gene, which is implicated in rigid spine muscular dystrophy, cause the classical phenotype of multiminicore disease: reassessing the nosology of early-onset myopathies. Am J Hum Genet 71: 739-749, 2002.

18. North $\mathrm{KN}$, Wang $\mathrm{CH}$, Clarke N, et al. Approach to the diagnosis of congenital myopathies. Neuromuscul Disord 24: 97-116, 2014.

19. Bergmann M, Kamarampaka M, Kuchelmeister K, Klein H, Koch H. Nemaline myopathy: two autopsy reports. Childs Nerv Syst 11: 610-615, 1995

The Internal Medicine is an Open Access journal distributed under the Creative Commons Attribution-NonCommercial-NoDerivatives 4.0 International License. To view the details of this license, please visit (https://creativecommons.org/licenses/ by-nc-nd/4.0/).

(C) 2021 The Japanese Society of Internal Medicine Intern Med 60: 2327-2332, 2021 